\title{
Leptin and obesity
}

\section{SETH ${ }^{1}$, R. BISWAS ${ }^{2}$, S. GANGULY ${ }^{3}$, N. CHAKRABARTI ${ }^{4}$ and A.G. CHAUDHURI ${ }^{3 *}$}

${ }^{1}$ Department of Physiology, Hiralal Mazumdar Memorial College for Women, Kolkata 700035, West Bengal, India

${ }^{2}$ Department of Physiology, Himachal Dental College, Sunder Nagar, Himachal Pradesh 175002, India

${ }^{3}$ Department of Physiology, Vidyasagar College, Kolkata 700006, West Bengal, India

${ }^{4}$ Department of Physiology, University of Calcutta, Kolkata 700009, West Bengal, India

Received: December 24, 2019 • Accepted: August 6, 2020

Published online: December 22, 2020

(c) 2020 Akadémiai Kiadó, Budapest

\section{ABSTRACT}

An imbalance between calorie intake and energy expenditure produces obesity. It has been a major problem in societies of the developing and developed world. In obesity an excessive amount of fat accumulates in adipose tissue cells as well as in other vital organs like liver, muscles, and pancreas. The adipocytes contain $o b$ genes and express leptin, a $16 \mathrm{kDa}$ protein. In the present communication, we reviewed the molecular basis of the etiopathophysiology of leptin in obesity. Special emphasis has been given to the use of leptin as a drug target for obesity treatment, the role of diet in the modulation of leptin secretion, and reduction of obesity at diminished level of blood leptin induced by physical exercise.

\section{KEYWORDS}

obesity, leptin, food intake, energy expenditure, leptin resistance, physical exercise

\section{INTRODUCTION}

Obesity is a major health issue in much of the human population [1]. Increasingly it has become a serious medical problem in developing nations due to urbanization and a more plentiful food supply [2]. Food intake is a complex behavior, which is determined by conscious decision-

\footnotetext{
"Corresponding author. E-mail: ghoshchaudhurialok@gmail.com
} 
making and subject to environmental factors such as the availability and properties of foods as well as social and cultural norms.

Appetite is a subjective feeling of the motivation to eat. Hunger and satiety can be overridden by desire. Our food preferences and eating patterns are molded by past experiences and also get influenced by sight, smell, and taste sensations. Eating behavior thus involves a complex interaction between different physiological processes [3].

Physiologically obesity is a disorder of energy balance, where energy in excess of its expenditure is stored as fat. The suppression of food intake and the increase in energy expenditure will therefore be very much effective for the treatment of obesity. It is also a part of the metabolic syndrome that increases the risk of abdominal fat deposition, insulin resistance, dyslipidemia, hypertension, coronary artery disease, fatty liver, gall stones, arthritis, cancer and may shorten the life span [4].

Several genes have been identified which can maintain body weight within a normal range. A key element of this system is 'leptin', the $16-\mathrm{kDa}$ hormonal product of the obese $(o b)$ gene, which was first identified in the year 1994 [5]. In humans, leptin is primarily secreted by white adipose tissues, which in fact corroborates its hormone function. Food intake and body weight are decreased by the action of leptin through its hypothalamic receptors [6]. Leptin increases insulin sensitivity and regulates glucose metabolism [7]. It acts as a growth factor in different cells [8] and in humans it regulates metabolic, neuroendocrine and immunological functions, which in turn maintain energy homeostasis [9]. In newborn infants, children, and adults, the amount of circulating leptin is generally proportional to fat mass, in which the amount of stored energy represents the balance between ingested calories and energy expenditure [5].

Leptin conveys information to the central nervous system (CNS) about the available energy stores in the body. The absence of leptin or its receptors therefore induces appetite and food intake that result in morbid obesity. Obese adults usually have elevated leptin levels, and leptin cannot induce weight loss due to cellular resistance to leptin [10]. However, leptin deficiency is found to occur in the exceptional cases of severe early childhood obesity. In the present communication we summarize the current understanding of the role of leptin in development and management of obesity at the cellular level.

\section{BIOLOGY OF LEPTIN}

\section{ob Gene}

The hormone leptin comes from the Greek word "leptos" meaning "thin". In humans leptin is encoded by the ob gene, which is located on chromosome 7 and comprises three exons and two introns spanning 20 kilobases $(\mathrm{kb})$ of genomic DNA [11]. Transcription of the leptin gene in mice yields a mRNA of about $3.5 \mathrm{~kb}$ that is expressed primarily in adipose tissues and also in placenta, ovaries, skeletal muscle, and stomach [12-15]. Leptin is synthesized as a 167 amino acid protein with a secretory signal sequence of 21 amino acid residues at the amino terminus. The signal sequence is functional, and results in the translocation of leptin into microsomes with subsequent removal of the signal peptide. Therefore the circulating leptin contains 146 amino acid residues [5]. A positive correlation exists between leptin mRNA and leptin protein levels in adipose tissue and plasma. Leptin is similar to cytokines. The structure of leptin consists of a 
complex of four helices and an intrachain disulphide bond, which is necessary for its biological activity $[16,17]$. Mutations of the $o b$ gene cause early onset of obesity in mice. Thus $o b / o b$ mouse mutants become leptin-deficient, hyperphagic, hypothermic, and exhibit morbid obesity with multiple metabolic and neuroendocrine anomalies. Human $o b$ gene mutations also cause similar changes along with hypothalamic hypogonadism [16].

\section{Leptin circulation}

Leptin circulates at a concentration of $5 \mathrm{mg} / \mathrm{ml}$ to $15 \mathrm{mg} / \mathrm{ml}$ in lean individuals. Women have higher circulating levels of leptin than men. Such sex difference may be associated with a stimulating role of estrogen or a suppressing role of androgens on leptin production [18]. Leptin circulates in plasma either as free adipokines or in bound form coupled to its receptor-binding proteins. In lean individuals the great majority of leptin circulates in the bound form, whereas in obese individuals it circulates in the free form [19].

\section{Regulation of Leptin Secretion}

Leptin synthesis is stimulated by insulin, cortisol, endotoxin, and cytokines like leukemia inhibitory factor (LIF) and interleukin-1 (IL-1). It is downregulated by catecholamines, thyroid hormone, testosterone, cAMP, and thiazolidine derivatives. In addition to these factors, tumor necrosis factor- $\alpha$ (TNF- $\alpha$ ) serves as a paracrine regulator to increase the secretion of leptin. Leptin can also autoregulate its own expression by glucose and fatty acids [16].

\section{Leptin receptor (ob-R) gene}

The leptin receptor (ob-R) gene was first isolated from mouse choroid plexus using an expression cloning strategy. Several splice variants of ob-R mRNA encode a minimum number of 6 isoforms of leptin receptors. Leptin receptor mutations cause early onset obesity accompanied by leptin insensitivity, hyperphagia, metabolic derangement, morbid obesity, and neuroendocrine abnormalities, including hypercorticism and hypothalamic hypogonadism. In humans this type of mutation brings about similar changes accompanied by impairment in the secretion of thyrotropin and growth hormone [16].

\section{Leptin receptors}

Leptin receptors belong to the cytokine class I receptor family. Several alternatively spliced isoforms of the leptin receptor have been identified (ob-Ra, ob-Rb, ob-Rc, ob-Rd, and ob-Re) [20]. Leptin receptor isoforms share an identical extracellular ligand binding domain at the amino terminus but differ at the carboxy terminus. Five isoforms, ob-Ra, ob-Rb, ob-Rc, ob-Rd, and ob-Re have transmembrane domains; however, only ob-Rb contains intracellular motifs required for its activity [16].

The ob-Ra is a leptin transporter and ob-Re is the soluble form of the transmembrane leptin receptor [21]. The long isoform of the leptin ob-Rb receptor consists of 1162 amino acids, with an intracellular signaling domain. It shows high peak concentrations in the feeding centers of the hypothalamus. The circulating leptin crosses the blood-brain barrier (BBB) to bind to its hypothalamic receptors and activates the JAK-STAT3 pathway. This suggests that leptin is the afferent signal informing the central nervous system about the body fat status. The neuronal- 
specific ablation of ob-Rb leads to obesity. On the other hand, high concentrations of the short isoforms of the ob-Ra and ob-Rc receptors are found in choroid plexus and brain microvessels, suggesting their role in BBB transport. The secreted isoform can be generated either by alternative splicing (ob-Re) or by ectodomain shedding, which may be involved in modulating leptin activity [20]. Moreover, leptin receptors are also found in different peripheral tissues viz. liver, heart, kidneys, lungs, small intestine, pituitary cells, testes, ovaries, spleen, pancreas and adrenal glands [22].

\section{Leptin signaling}

The structure of leptin is related to that of the long-chain helical cytokine family. The main channel of this gene is JAK/STAT. It acts via two groups of arcuate neurons, which are located in the hypothalamus region of the brain. The first group expresses agouti-related peptide (AgRP) and neuropeptide Y (NPY) and the second group expresses pro-opiomelanocortin (POMC) and cocaine and amphetamine-related transcript (CART) [23].

Binding of leptin to its long form of the surface membrane receptor (ob- $\mathrm{Rb}$ ) of the target cells causes dimerization of its receptors, which in turn activates the JAK/STAT pathway [24]. The activated JAKs phosphorylate tyrosine sites on the intracellular domain of the receptor, which serve as docking sites for the Src-homology domains (SH2, SH3) that occur in all of the STATs. The phosphorylated intracellular domain has a binding site for STAT protein. The activated STAT proteins undergo dimerization and then translocate to the nucleus. The activation, dimerization, and nuclear translocation of STAT3 enhances POMC gene expression and inhibits AgRP gene expression. Accordingly, POMC neurons deficient in STAT3 result in enhanced bodyweight. This signaling pathway is negatively controlled by the suppression of cytokine signaling 3 (SOCS3), the expression of which is in turn under the regulation of the activities of STAT3 and protein tyrosine phosphatase 1B (PTP1B). Consistent with this, deletion of either SOCS3 or PTP1B (Ptpn1) in POMC neurons leads to reduced adiposity, improved leptin sensitivity, and increased energy expenditure [25]. ob-Rb activation may also phosphorylate JAK leading to the activation of insulin receptor substrate (IRS-1) and mitogenactivated protein kinase (MAPK) [2].

Upon binding of leptin to its ob-Ra receptor, IRS- 1 gets phosphorylated and activates MAPK, resulting in the activation of pp90S6-K [25]. In addition, leptin also stimulates the phosphatidylinositol-3-kinase (PI3K) pathway. PI3K generates phosphatidylinositol-3,4,5triphosphate (PIP3) and activates downstream targets such as phosphoinositide-dependent kinase 1 (PDK1) and AKT (also known as protein kinase B), which consecutively phosphorylate the transcription factor forkhead box protein O1 (FOXO1). Upon phosphorylation, FOXO1 is excluded from the nucleus, allowing STAT3 to bind to POMC and AgRP promoters, thereby stimulating and inhibiting, respectively, the expression of these neuropeptides [26]. PI3K signaling is counterbalanced by phosphatase and tensin homolog (PTEN), which specifically dephosphorylate PIP3. The loss of PTEN in POMC neurons brings about increased PIP3 signaling and diet-sensitive obesity via $\mathrm{K}_{\mathrm{ATP}}$ channel modulation, suggesting a role for the PI3K pathway in the regulation of the activity of this channel [25]. Thus, leptin stimulates POMC transcription and depolarizes POMC neurons. It also increases a-MSH processing and secretion and attenuates the expression and release of orexigenic NPY and AgRP neuropeptides [3]. 


\section{IMPLICATIONS OF LEPTIN IN OBESITY}

Leptin is the chemical mediator in the brain responsible for the conditions of energy imbalance, such as obesity. The most important variable that determines circulating leptin concentrations is body fat mass [27]. When eating cycles are regular, an exponential relationship exits between the level of leptin and the proportion of adipose tissue. Human obesity is related with hyperleptinemia and the circulating leptin concentrations are predicted by the body mass index (BMI). The ob gene is expressed in different fat compartments of the body. Approximately $5 \%$ of obese populations can be regarded as "relatively" leptin deficient, which would benefit from leptin therapy [20].

Leptin has dual regulation in human physiology. During the time of weight maintenance, the intake of energy is equal to the energy output, and leptin concentrations reflect total body fat mass. However, in the cases of negative (weight-loss programs) and positive (weight-gain programs) energy balances, the changes in leptin concentrations act as a sensor of energy imbalance [20]. In absolute leptin deficiency, individuals with heterozygous leptin gene mutations have low circulating concentrations of leptin resulting in an increase in body adiposity [20]. Independent of fat mass, low soluble leptin receptor concentrations and a low ratio of bound to free leptin have been found in individuals with insulin resistance and abdominal obesity. On the other hand, low soluble receptor concentrations and a low fraction of specifically bound leptin are the markers of leptin resistance, which are independently associated with insulin resistance and abdominal obesity [28]. Leptin can regulate adipocyte mass and modulate immune responses including chronic inflammation in peripheral tissues. Thus, obesity is strongly associated with inflammatory state as evidenced by high levels of cytokines and inflammatory markers within the body [29].

\section{EFFECTS OF LEPTIN IN FASTING CONDITION}

The dominance of leptin in energy homeostasis acts as a mediator of adaptation to fasting. When both lean and obese individuals undergo short-term fasting, there is a larger decrease in free leptin concentrations in lean subjects than in obese individuals. In obese individuals leptin concentration in the cerebrospinal fluid increases modestly and the ratio of leptin in the cerebrospinal fluid to that in serum decreases logarithmically with increasing BMI [30]. Leptindeficient $o b / o b$ mice exhibit similar metabolic, neuroendocrine, and immune abnormalities as those resulting from starvation. These changes suggest that leptin deficiency is perceived as a state of continuous starvation in ob/ob mice, and also that the fall in leptin level mediates the adaptation to fasting by regulating the hypothalamic-pituitary-adrenal axis [16], and evokes profound changes in energy balance and hormone levels. This in turn limits the use of energy and enhances energy storage in the form of fat. Thus, leptin provides protection against starvation [3].

\section{EFFECTS OF LEPTIN ON FOOD INTAKE}

Leptin plays a key role in the control of food intake. Several studies have demonstrated that in rodents leptin is transported into the brain and binds to its receptor in the hypothalamus to activate the JAK-STAT3 pathway. This in turn results in the suppression of "orexigenic 
peptides" (e.g., NPY, AgRP, and GABA which normally increase food intake), and stimulation of "anorexigenic peptides" (e.g., POMC and CART which normally decrease food intake) [3].

The hyperphagic behavior is evident in $o b / o b$ and $d b / d b$ mice. Food intake gets significantly suppressed in $o b / o b$ mice when leptin is injected into them either centrally or peripherally. Disruption of the LepR/STAT3 pathway produces hyperphagia. Multiple neuronal populations and neurocircuits on which leptin can act regulate food intake and energy balance. The disruption of LepR expression exclusively in POMC/CART or NPY/AgRP/GABA neurons exerts profound effects on food intake and energy balance. In the lateral hypothalamic area (LHA) there are some neurons which express the neuropeptides melanin-concentrating hormone $(\mathrm{MCH})$ or orexin (also known as hypocretin). These cells do not express the LepR and stimulate feeding. On the other hand, the neurotensin-positive neurons of LHA express LepR, and the ablation of LepR in these cells increases food intake. Leptin acts in LHA neurotensin neurons resulting in the inhibition of orexin neurons. In addition, in mice the pharmacogenetic activation of LepR-expressing neurons in the median preoptic area (MPO) causes a massive suppression of food intake. Dopamine neurons in the ventral tegmental area (VTA) express LepR and thus the direct administration of leptin to the VTA leads to a decrease in food intake [31]. LepR-expressing cells in the nucleus tractus solitarious (NTS) also express different neurochemical markers like POMC, cholecystokinin (CCK) and glucagon-like peptide-1 (GLP-1) [32]. Selective inactivation of LepR in Phox2b-positive cells causes LepR deletion in NTS GLP-1 neurons. This genetic manipulation generates mice that display increased food intake after fasting, indicating that leptin action on GLP-1 neurons also controls food intake [33].

Leptin also plays a role in short-term regulation of food intake and body weight. In addition to adipose tissue, leptin is also produced by the stomach in small amounts [15]. The conservation of leptin across different species and diverse organs points to the functional relevance of this adipokine [34]. Leptin plays a role in the control of meal size; several intestinal peptides as well as insulin stimulate the release of leptin from the stomach. The pancreatic hormone insulin is secreted into the bloodstream shortly after the intake of food. Furthermore, high-fat meals and mixed meals decrease the circulating leptin levels in a day. Thus gastric leptin acts as a local stimulus in the intestinal digestion and absorption of the ingested foods [35].

\section{EFFECTS OF LEPTIN ON ENERGY EXPENDITURE AND THERMOGENESIS}

In humans there are two classes of adipose tissues, namely white adipose tissue (WAT) and brown adipose tissue (BAT). During fasting the chemical energy stored in the form of triacylglycerols in the WAT is utilized. BAT contains triacylglycerols, large numbers of mitochondria and profuse sympathetic adrenergic innervation which are responsible for its brown color. The uncoupling protein 1 (UCP1) expressed by BAT causes its mitochondria to release the energy as heat by the oxidation of macronutrients $[36,37]$. In obese humans there is a reduction in or absence of the amount and activity of BAT [38].The process by which WAT is converted to BAT by increasing the number of its mitochondria and the expression of UCP1 is called "browning". This process increases energy expenditure and inhibits high-fat diet-induced obesity in rodents [39]. Nowadays BAT is a potential target for obesity treatment. [40].

Leptin has potential effects on energy expenditure. ob/ob mice show high metabolic efficiency due to low energy expenditure, which can be corrected by leptin replacement in these 
mice [31]. Actually, the regulation of energy expenditure by leptin depends on multiple neuronal populations. The ablation of LepR in AgRP neurons or in POMC and AgRP cells causes obesity in adult mice due to alteration in energy expenditure without affecting the food intake [41]. Leptin also acts on the dorsomedial nucleus of the hypothalamus (DMH) and increases sympathetic tone to brown adipose tissue (BAT) as well as interscapular BAT temperature $[42,43]$. The selective disruption of LepR in DMH neurons causes obesity due to low energy expenditure and the inhibition of thermogenic responses to leptin, without affecting food intake [44, 45]. In humans leptin acts on POMC neurons to promote the browning of WAT as well as energy expenditure and also to depress appetite [40].

Leptin regulates energy balance through its actions in the hypothalamus. Despite high circulating levels of leptin in obese people, the hypothalamus does not sensitize leptin to suppress appetite or to increase energy expenditure probably due to an abnormal transit across the $\mathrm{BBB}$ at the arcuate nucleus, hypothalamic endoplasmic reticulum (ER) stress, maladaptive sterile inflammation in the hypothalamus, and overexpression of molecules that may inhibit leptin signaling. In addition, the NSAPP pathway (consisting of five protein components) is needed for the complete signaling of leptin in neurons and in the case of obesity this pathway cannot function properly. Thus in obesity leptin cannot exhibit its appetite-suppressing effects resulting in leptin resistance [36].

\section{LEPTIN RESISTANCE AND OBESITY}

Obesity is characterized by a condition of leptin resistance. The failure of high endogenous leptin to normalize body weight in obese individuals has suggested the possibility of development of leptin resistance in obesity [46]. The obese human shows elevated levels of leptin in serum and adipocytes, and exhibits limited effects with leptin treatment due to leptin-resistance. In diet-induced obesity (DIO) overeating causes an increase in circulating leptin levels leading to a reduced sensitivity of the hypothalamus to leptin [31]. In addition, rats develop leptin resistance in chronic leptin infusion which also reduces their body weight, adiposity, and food intake. In contrast, LepR antagonist administration surprisingly increases feeding and body weight in both lean and DIO mice [47]. Obesity also reduces the anorexigenic effects of leptin [31]. The intraperitoneal administration of leptin induces an equivalent number of cells expressing pSTAT3 in the VMH, DMH, and NTS of high fat diet-induced obese mice, compared to lean animals on normal chow diet. The anatomical position of LepR-expressing cells in relation to the $\mathrm{BBB}$ is the probable cause of selective leptin resistance [48], and this type of resistance may be also present in peripheral tissues [49].

Leptin enters into the CNS through a saturated transport system. The cerebrospinal fluid to serum leptin ratio is decreased in obesity. Central leptin infusions are more efficient than peripheral injections in inducing the anorexigenic effects of leptin in obese animals. This suggests that leptin is transported from systemic circulation to the CNS by the short forms of LepR, namely obRa, and mutant rats with a deficiency of synthesizing obRa develop obesity due to decreased leptin transport across the BBB [31]. In addition, the obRa present in brain microvessels and choroid plexus mediates the transcellular transport of leptin. Circulating leptin activates ERK signaling pathway in median eminence tanycytes and allows leptin passage to the cerebrospinal fluid [50]. The activation of the LepR/JAK2/STAT3 signaling pathway induces a 
robust expression of STAT transcription factors, which in turn regulate the transcription of genes from the SOCS family, including 8 intracellular proteins named SOCS1 to SOCS7, and CIS. The major protein SOCS3 inhibits leptin signaling, and the increased SOCS3 levels in LepR-expressing cells is the principal cause of leptin resistance in obesity [31].

In addition, protein tyrosine phosphatases (PTPs) catalyze the dephosphorylation of tyrosine residues and inhibit leptin signaling through the dephosphorylation of LepR, JAK2 or STAT3 [51]. The hypothalamic expression of PTPs is increased in obese animals, and selective ablation of these proteins improves leptin sensitivity and partially prevents high fat DIO and insulin resistance [52].

Leptin resistance is caused by mutations in the genes encoding leptin and its receptors as well as proteins involved in the self-regulation of leptin synthesis and the permeability of BBB [53]. Thus a number of potential mechanisms, which impair LepR signaling in obesity and permit positive energy balance, are the obesity-induced inhibitors of the LepR signaling pathway, the activation of inflammatory signaling pathways and cytokines or ER stress in the hypothalamus or hypothalamic gliosis [46].

\section{LEPTIN AS A DRUG TARGET FOR OBESITY}

Leptin has a potential role as a therapeutic target. The discovery of any treatment capable of preventing or curing the condition of leptin resistance will have a tremendous potential as antiobesity therapy [54]. Fc-leptin is used for the treatment of non-leptin-deficient obese humans [35]. In healthy humans leptin causes ongoing weight loss after 12 weeks of dietary fat restriction [55]. The intracellular protein SOCS3 is a potential target for therapeutic intervention, because it acts as a leptin-induced negative regulator of leptin receptor signaling and an effective mediator of leptin resistance [56]. In addition, in human obesity PTP1B (a leptin-resistance-inducing protein) has also been suggested to be a potential target for the treatment of leptin resistance [35]. Many natural products containing several lignans and flavonoids can inhibit PTP1B [57]. Resveratrol activates SIRT1, a NAD ${ }^{+}$-dependent protein deacetylase, which modulates leptin and insulin sensitivity [58]. Celastrol, a pentacyclic triterpene, or withaferin A, a steroidal lactone, are leptin sensitizer compounds and have powerful anti-obesity properties [59, 60]. In addition, concurrent peripheral administration of leptin and amylin (a hormone co-secreted with insulin from pancreatic $\beta$-cells that binds to specific receptors in the hindbrain) causes synergistic anorexigenic effects in DIO animals. This indicates that amylin agonists restore leptin responsiveness in DIO. Exendin-4 (a long-acting GLP-1 receptor agonist) or fibroblast growth factor also induces leptin responsiveness in DIO mice. Moreover, treatment of obese mice by leptinneutralizing antibodies for 6 weeks has been found to result in a 10\% reduction of food intake [61]. Recent clinical data also suggest that obesity, disturbed glucose homeostasis and sleep apnea are interrelated phenomena, and treating one of them can improve the others [62].

\section{MODULATION OF DIET TO STIMULATE THE SECRETION OR ENHANCE THE ACTION OF LEPTIN}

Diet plays an important role in controlling obesity. Regarding meal composition, which is a determinant of leptin level in obese humans, low-fat/high-carbohydrate meals result in an 


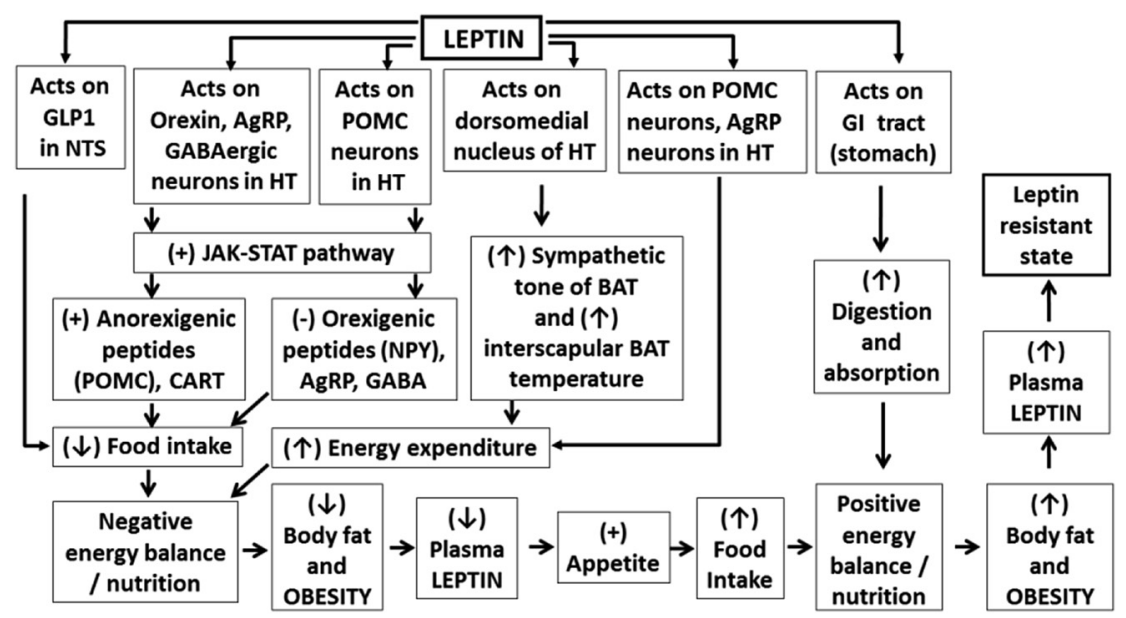

Fig. 1. An idealized model depicting the mode of leptin actions in developing obesity. HT, Hypothalamus; POMC, Pro-opiomelanocortin; AgRP, Agouti-related peptide; GABA, $\gamma$-Aminobutyric acid; GLP1, Glucagon-like peptide 1; NTS, Nucleus tractus solitarius; BAT, Brown adipose tissue; NPY, Neuropeptide Y; CART, Cocaine and amphetamine-related transcript

increase in circulating leptin concentrations compared with high-fat/low-carbohydrate meals [35]. It has been found that intake of carbohydrates with high glycemic index increases leptin concentration [63]. The presence of high amount of fibers in the diet enhances leptin sensitivity as well as controls the secretion of leptin [64]. Diets enriched with $\omega 3$ and $\omega 6$ polyunsaturated fatty acids (PUFA) cause the increase in the circulating level of leptin compared to a diet enriched in monounsaturated fatty acids (MUFA) and saturated fatty acids (SFA) [65]. When protein consumption is higher, it increases satiety, leptin concentration as well as leptin sensitivity in the central nervous system to control body weight [66] (Fig. 1).

\section{LEPTIN AND PHYSICAL EXERCISE}

In obese women a 9-week aerobic exercise program did not change resting serum leptin levels, suggesting that women with a higher degree of obesity have a higher degree of leptin resistance and a larger volume of exercise is needed to affect the levels of leptin [67]. Perusse et al. 1997 [68] showed that in men a 20 -week aerobic exercise program significantly decreased leptin concentrations. Different studies suggest that long-term exercise ( $\geq 60 \mathrm{~min})$ and exercises that cause energy expenditure equal to or higher than $800 \mathrm{kcal}$ decrease the circulating leptin concentration [69], whereas short-term exercises $(<60 \mathrm{~min})$ and exercises that cause energy expenditure lower than $800 \mathrm{kcal}$ fail to modify the levels of circulating leptin [70]. Regarding the effects of exercise training on circulating leptin, it has been found that in healthy young and older males short-term aerobic training for 7 successive days does not modify leptin concentrations [71], whereas a reduction in leptinemia has been found after 3 weeks of military training, but the body weight remains stable [72]. Thus circulating leptin shows different 
responses to short-term ( $<12$ weeks) and long-term training ( $\geq 12$ weeks) [69], and during exercise leptin regulates the energy balance by increasing energy expenditure as well as reducing total body fat [73]. It has been suggested that the decrease in the level of insulin, the known stimulant of the expression of leptin in adipose tissue, takes place prior to the reduction of leptin and thus it may be considered as a mediator of leptin concentrations [74]. Although exercise improves leptin sensitivity in peripheral tissues or in the hypothalamus in obese animals, acute exercise suppresses hypothalamic PTP1B protein levels, resulting in more activation of insulin and leptin signaling pathways in obese rats [31].

\section{ADIPOSE TISSUE IMMUNITY, LEPTIN, AND CANCER}

In case of excess energy consumption with little or no physical exercise, obese individuals may sometimes develop proinflammatory condition in their adipose tissue cells due to infiltration of monocytes, macrophages, neutrophils and mast cells from the innate and B and $\mathrm{T}$ lymphocytes from the acquired immune system [75]. Furthermore, the intracellular accumulation of interferon- $\gamma$, monocyte chemotactic protein-1, tumor necrosis factor $\alpha$, interleukin -6 and $-1 \beta$ transform the proinflammatory condition into a state of inflammation [76]. All these changes create a microenvironment in the adipocytes upon which leptin can act as the mitogenic, antiapoptotic, and angiogenic signaling molecule to promote carcinogenesis [77].

Leptin has been found to be associated with breast, ovarian, endometrial, prostate, colorectal, lung, pancreatic, adrenal, pituitary, and thyroid cancers [75-78]. After menopause in women, the adipose tissues serve as the main source of estrogen. Postmenopausal obese women are more prone to develop breast cancer than premenopausal lean women, indicating the existence of positive correlations between blood titers of leptin and estrogen, and also the tissue-specific expression of their receptors $[79,80]$. In addition, leptin can regulate the expression of several proteins viz. p53, cyclin D1, E-cadherin, survivin, vascular endothelial growth factor and its receptor subtype 2 involved in carcinogenesis, and also stimulate the production of interleukin- 8 and -18 by macrophages for cancer metastasis [80].

\section{FUTURE PERSPECTIVES}

It is obvious from the discussion that calorie intake, diet therapy and physical exercise maintain a complex relationship among themselves. Keeping this in consideration, the following studies may be envisaged to restrict the problems of obesity within a physiological limit.

(a) Due to blunted response of leptin to calorie intake the leptin resistance state develops. The ability of leptin replacement to reverse the obesity-related changes suggests that leptin itself or drugs stimulating the leptin signaling pathway may provide opportunities for the maintenance of weight loss.

(b) On the other hand, how supplementation of weight-reducing substances in diet along with or without training programs of physical exercise can influence the action of leptin in target cells may be another subject for future study. 


\section{REFERENCES}

1. Chooi YC, Ding C, Magkos F. The epidemiology of obesity. Metabolism 2019; 92: 6-10.

2. Margetic S, Gazzola C, Pegg GG, Hill RA. Leptin: a review of its peripheral actions and interactions. Int J Obes Relat Metab Disord 2002; 26: 1407-33.

3. Ahima RS. Revisiting leptin's role in obesity and weight loss. J Clin Invest 2008; 118: 2380-83.

4. Yang R, Barouch LA. Leptin signaling and obesity: cardiovascular consequences. Circul Res 2007; 101: 545-59.

5. Zhang Y, Proenca R, Maffei M, Barone M, Leopold L, Friedman JM. Positional cloning of the mouse obese gene and its human homologue. Nature 1994; 372: 425-32.

6. Bouret SG, Draper SJ, Simerly RB. Trophic action of leptin on hypothalamic neurons that regulate feeding. Science 2004; 304: 108-10.

7. Koopmans SJ, Frolich M, Gribnau EH, Westendorp RGJ, DeFronzo RA. Effect of hyperinsulinemia on plasma leptin concentrations and food intake in rats. Am J Physiol Endocrinol Metab 1998; 274: E998-1001.

8. Gainsford T, Willson TA, Metcalf D, Handman E, McFarlane C, Ashley Ng A, et al. Leptin can induce proliferation, differentiation, and functional activation of hemopoietic cells. Proc Natl Acad Sci USA 1996; 93: 14564-68.

9. Palou A, Serra F, Bonet ML, Picó C. Obesity: molecular bases of a multifactorial problem. Eur J Nutr 2000; 39: $127-44$.

10. Münzberg H. Leptin-signaling pathways and leptin resistance. Forum Nutr 2010; 63: 123-32.

11. Wasim M. Role of leptin in obesity. J Obes Weight Loss Ther 2015; 5;258. https://doi.org/10.4172/2165-7904. 1000258.

12. Hoggard N, Hunter L, Duncan JS, Williams LM, Trayhurn P, Mercer JG. Leptin and leptin receptor mRNA and protein expression in the murine fetus and placenta. Proc Natl Acad Sci USA 1997; 94: 11073-78.

13. Spicer LJ, Francisco CC. The adipose obese gene product, leptin: evidence of a direct inhibitory role in ovarian function. Endocrinology 1997; 138: 3374-79.

14. Wang J, Liu R, Hawkins M, Barzilai N, Rossetti L. A nutrient-sensing pathway regulates leptin gene expression in muscle and fat. Nature 1998; 393: 684-88.

15. Bado A, Levasseur S, Attoub S, Kermorgant S, Laigneau JP, Bortoluzzi MN, et al. The stomach is a source of leptin. Nature 1998; 394: 790-93.

16. Ahima RS, Flier JS. Leptin. Annual Rev Physiol 2000; 62: 413-37.

17. Zhang F, Chen Y, Heiman M, Di Marchi R. Leptin: structure, function and biology. Vitam Horm 2005; 7: $345-72$.

18. Carter ME, Soden ME, Zweifel LS, Palmiter RD. Genetic identification of a neural circuit that suppresses appetite. Nature 2013; 503: 111-14.

19. Brabant G, Nave H, Mayr B, Behrend M, van Harmelen V, Arner P. Secretion of free and protein-bound leptin from subcutaneous adipose tissue of lean and obese women. J Clin Endocrinol Metab 2002; 87: 3966-70.

20. Meier U, Gressner AM. Endocrine regulation of energy metabolism: review of pathobiochemical and clinical chemical aspects of leptin, ghrelin, adiponectin, and resistin. Clin Chem 2004; 50: 1511-25.

21. Huang L, Wang JW, Li C. Modulation of circulating leptin levels by its soluble receptor. J Biol Chem 2001; 276: 6343-49.

22. Hedef EYD. Leptin: a new aspect of a multifunctional protein. Al-Mustansiriyah J Pharm Sci 2004; 1: 72-85.

23. Fatima W, Shahid A, Imran M, Manzoor J, Hasnain S, Rana S, et al. Leptin deficiency and leptin gene mutations in obese children from Pakistan. Int J Padiatr Obes 2011; 6: 419-27.

24. Frühbeck G. Intracellular signalling pathways activated by leptin. Biochem J 2006; 393: 7-20. 
25. Schneeberger M, Gomis R, Claret M. Hypothalamic and brainstem neuronal circuits controlling homeostatic energy balance. J Endocrinol 2014; 220: 25-46.

26. Kitamura T, Feng Y, Kitamura YI, Chua SC, , Jr., Xu AW, Barsh GS, et al. Forkhead protein FoxO1 mediates Agrp-dependent effects of leptin on food intake. Nat Med 2006; 12: 534-40.

27. Speakman JR, Stubbs RJ, Mercer JG. Does body mass play a role in the regulation of food intake? Proc Nutr Soc 2002; 61: 473-87.

28. Sandhofer A, Laimer M, Ebenbichler CF, Kaser S, Paulweber B, Patsch JR. Soluble leptin receptor and soluble receptor-bound fraction of leptin in the metabolic syndrome. Obes Res 2003; 11: 760-68.

29. Cortese L, Terrazzano G, Pelagalli A. Leptin and immunological profile in obesity and its associated diseases in dogs. Int J Mol Sci 2019; 20: 2392. https://doi.org/10.3390/ijms20102392.

30. Kurrimbux D, Gaffen Z, Far-el CL, Martin D, Thomas SA. The involvement of the blood-brain and the blood-cerebrospinal fluid barriers in the distribution of leptin into and out of the rat brain. Neuroscience 2004; 123: 527-36.

31. Ramos-Lobo AM, Jose D, Jr. The role of leptin in health and disease. Temp 2017; 4: 258-91.

32. Garfield AS, Patterson C, Skora S, Gribble FM, Reimann F, Evans ML, et al. Neurochemical characterization of body weight-regulating leptin receptor neurons in the nucleus of the solitary tract. Endocrinol 2012; 153: 4600-07.

33. Scott MM, Williams KW, Rossi J, Lee CE, Elmquist JK. Leptin receptor expression in hindbrain Glp-1 neurons regulates food intake and energy balance in mice. J Clin Invest 2011; 121: 2413-21.

34. Muruzábal FJ, Frühbeck G, Gómez-Ambrosi J, Archanco M, Burrell MA. Immunocytochemical detection of leptin in non-mammalian vertebrate stomach. General Comparative Endocrinol 2002; 128: 149-52.

35. Klok MD, Jacobsdottir S, Drent ML. The role of leptin and ghrelin in the regulation of food intake and body weight in humans: a review. Obes Review 2007; 8: 21-34.

36. Fruhwürth S, Vogel H, Schürmann A, Williams KJ. Novel insights into how overnutrition disrupts the hypothalamic actions of leptin. Front Endocrinol 2018; 9: 89. https://doi.org/10.3389/fendo.2018.00089.

37. Larabee CM, Neely OC, Domingos AI. Obesity: a neuroimmunometabolic perspective. Nat Rev Endocrinol 2020; 16: 30-43.

38. Ouellet V, Routhier-Labadie A, Bellemare W, Lakhal-Chaieb L, Turcotte E, Carpentier AC, et al. Outdoor temperature, age, sex, body mass index, and diabetic status determine the prevalence, mass, and glucoseuptake activity of ${ }^{18}$ F-FDG-detected BAT in humans. J Clin Endocrinol Metabol 2011; 96: 192-99.

39. Stadion M, Schwerbel K, Graia A, Baumeier C, Rödiger M, Jonas W, et al. Increased Ifi202b/IFI16 expression stimulates adipogenesis in mice and humans. Diabetologia 2018; 61: 1167-79.

40. Dodd GT, Decherf S, Loh K, Simonds SE, Wiede F, Balland E, et al. Leptin and insulin act on POMC neurons to promote the browning of white fat. Cell 2015; 160: 88-104.

41. van de Wall E, Leshan R, Xu AW, Balthasar N, Coppari R, Liu SM, et al. Collective and individual functions of leptin receptor modulated neurons controlling metabolism and ingestion. Endocrinol 2008; 149: 1773-85.

42. Enriori PJ, Sinnayah P, Simonds SE, Garcia Rudaz C, Cowley MA. Leptin action in the dorsomedial hypothalamus increases sympathetic tone to brown adipose tissue in spite of systemic leptin resistance. J Neurosci 2011; 31: 12189-97.

43. Zhang Y, Kerman IA, Laque A, Nguyen P, Faouzi M, Louis GW, et al. Leptin-receptor-expressing neurons in the dorsomedial hypothalamus and median preoptic area regulate sympathetic brown adipose tissue circuits. J Neurosci 2011; 31: 1873-84.

44. Dodd GT, Worth AA, Nunn N, Korpal AK, Bechtold DA, Allison MB, et al. The thermogenic effect of leptin is dependent on a distinct population of prolactin-releasing peptide neurons in the dorsomedial hypothalamus. Cell Metab 2014; 20: 639-49. 
45. Rezai-Zadeh K, Yu S, Jiang Y, Laque A, Schwartzenburg C, Morrison CD, et al. Leptin receptor neurons in the dorsomedial hypothalamus are key regulators of energy expenditure and body weight, but not food intake. Molecul Metab 2014; 3: 681-93.

46. Pan W, Myers M. Leptin and the maintenance of elevated body weight. Nat Rev Neurosci 2018; 19: 95-105.

47. Ottaway N, Mahbod P, Rivero B, Norman LA, Gertler A, D’Alessio DA, et al. Diet-induced obese mice retain endogenous leptin action. Cell Metab 2015; 21: 877-82.

48. Münzberg H, Flier JS, Bjørbæk C. Region-specific leptin resistance within the hypothalamus of diet-induced obese mice. Endocrinol 2004; 145: 4880-89.

49. Sáinz N, Barrenetxe J, Moreno-Aliaga MJ, Martínez JA. Leptin resistance and diet-induced obesity: central and peripheral actions of leptin. Metabolism 2015; 64: 35-46.

50. Balland E, Dam J, Langlet F, Caron E, Steculorum S, Messina A, et al. Hypothalamic tanycytes are an ERKgated conduit for leptin into the brain. Cell Metabol 2014; 19: 293-301.

51. St-Pierre J, Tremblay ML. Modulation of leptin resistance by protein tyrosine phosphatases. Cell Metabol 2012; 15: 292-97.

52. Tsou RC, Zimmer DJ, De Jonghe BC, Bence KK. Deficiency of PTP1B in leptin receptor-expressing neurons leads to decreased body weight and adiposity in mice. Endocrinol 2012; 153: 4227-37.

53. Gruzdeva O, Borodkina D, Uchasova E, Dyleva Y, Barbarash O. Leptin resistance: underlying mechanisms and diagnosis. Diabetes Metab Syndr Obes 2019; 12: 191-98.

54. Roujeau C, Jockers R, Dam J. New pharmacological perspectives for the leptin receptor in the treatment of obesity. Front Endocrinol 2014; 5: 167. https://doi.org/10.3389/fendo.2014.00167.

55. Weigle DS, Cummings DE, Newby PD, Breen PA, Frayo RS, Matthys CC, et al. Roles of leptin and ghrelin in the loss of body weight caused by a low fat, high carbohydrate diet. J Clin Endocrinol Metab 2003; 88: 1577-86.

56. Mori H, Hanada R, Hanada T, Aki D, Mashima R, Nishinakamura H, et al. Socs3 deficiency in the brain elevates leptin sensitivity and confers resistance to diet-induced obesity. Nat Med 2004; 10: 739-43.

57. Hung HY, Qian K, Morris-Natschke SL, Hsu CS, Lee KH. Recent discovery of plant-derived anti-diabetic natural products. Nat Prod Report 2012; 29: 580-606.

58. Sasaki T. Age-associated weight gain, leptin, and SIRT1: a possible role for hypothalamic SIRT1 in the prevention of weight gain and aging through modulation of leptin sensitivity. Front Endocrinol 2015; 6: 1-10.

59. Liu J, Lee J, Salazar Hernandez MA, Mazitschek R, Ozcan U. Treatment of obesity with celastrol. Cell 2015; 161: 999-1011.

60. Lee J, Liu J, Feng X, Salazar Hernandez MA, Mucka P, Ibi D, et al. Withaferin A is a leptin sensitizer with strong antidiabetic properties in mice. Nat Med 2016; 22: 1023-32.

61. Zhao S, Zhu Y, Schultz RD, Li N, He Z, Zhang Z, et al. Partial leptin reduction as an insulin sensitization and weight loss strategy. Cell Metabolism 2019; 30: 706-19.

62. Pugliese G, Barrea L, Laudisio D, Salzano C, Aprano S, Colao A, et al. Sleep apnea, obesity, and disturbed glucose homeostasis: epidemiologic evidence, biologic insights, and therapeutic strategies. Curr Obes Rep 2020; 9: 30-8.

63. Herrmann TS, Bean ML, Black TM, Wang P, Coleman RA. High glycemic index carbohydrate diet alters the diurnal rhythm of leptin but not insulin concentrations. Exp Biol Med 2001; 226: 1037-44.

64. Jensen MK, Koh-Banerjee P, Franz M, Sampson L, Gronback M, Rimun EB. Whole grains, bran, and germ in relation to homocysteine and markers of glycemic control, lipids, and inflammation. Am J Clin Nutr 2006; 83: 275-83.

65. Cha MC, Jones PJH. Dietary fat type and energy restriction interactively influence plasma leptin concentration in rats. J Lipid Res 1998; 39: 1655-60. 
66. Weigle DS, Breen PA, Matthys CC, Callahan HS, Meeuws KE, Burden VR, et al. A high-protein diet induces sustained reductions in appetite, ad libitum caloric intake, and body weight despite compensatory changes in diurnal plasma leptin and ghrelin concentrations. Am J Clin Nutrition 2005; 82: 41-8.

67. Kraemer RR, Kraemer GR, Acevedo EO, Hebert EP, Temple E, Bates M, et al. Effects of aerobic exercise on serum leptin levels in obese women. Eur J Appl Physiol Occuptional Physiol 1999; 80: 154-58.

68. Pérusse L, Collier G, Gagnon J, Leon AS, Rao DC, Skinner JS, et al. Acute and chronic effects of exercise on leptin levels in humans. J Appl Physiol 1997; 83: 5-10.

69. Bouassida A, Zalleg D, Bouassida S, Zaouali M, Feki Y, Zbidi A, Tabka Z. Leptin, its implication in physical exercise and training: a short review. J Sports Sci Med 2006; 5: 172-81.

70. Kraemer RR, Chu H, Castracane VD. Leptin and exercise. Exp Biol Med 2002; 227: 701-08.

71. Houmard JA, Cox JH, Mac-Lean PS, Barakat HA. Effect of short-term exercise training on leptin and insulin action. Metabolism 2000; 49: 858-61.

72. Gomez-Merino D, Chennaoui M, Drogou C, Bonneau D, Guezennec CY. Decrease in serum leptin after prolonged physical activity in men. Med Sci Sports Exercise 2002; 34: 1594-99.

73. Karacabey K. The effect of exercise on leptin, insulin, cortisol and lipid profiles in obese children. J International Med Res 2009; 37: 1472-78.

74. Abedi B. Acute effect of concurrent exercise on serum leptin and resistance insulin response in sedentary men. Int Arch Health Sci 2020; 7: 14-9.

75. Catalan V, Gomez-Ambrosi J, Rodriguez A, Fruhbeck G.Adipose tissue immunity and cancer. Frontiers Physiol 2013; 4: 275. https://doi.org/10.3389/fphys.2013.00275.

76. Perez-Hernandez AI, Catalan V, Gomez-Ambrosi J, Rodriguez A, Fruhbeck G. Mechanisms linking excess adiposity and carcinogenesis promotion. Frontiers in Endocrinol (Lausanne) 2014; 5: 65. https://doi.org/10. 3389/fendo.2014.00065.

77. Garofalo C, Surmacz E. Leptin and cancer. J Cellular Physiol 2006; 207: 12-22.

78. Dutta D, Ghosh S, Pandit K, Mukhopadhyay P, Chowdhury S. Leptin and cancer: pathogenesis and modulation. Ind J Endocrinol Metab 2012; 16: S596-600.

79. Atoum MF, Alzoughool F, Al-Hourani H. Linkage between obesity leptin and breast cancer. Breast Cancer: Basic Clinic Res 2020; 14: 1-8.

80. Sanchez-Jimenez F, Perez-Perez A, Cruz-Merino L de la, Sanchez-Margalet V. Obesity and breast cancer: role of leptin. Frontiers in Oncology 2019; 9: 596. https://doi.org/10.3389/fonc.2019.00596. 